\title{
THE INDICATIONS AND TECHNIQUE OF IRIDENCLEISIS*
}

\author{
BY \\ G. P. SOURDILle \\ Nantes, France
}

FEw surgical techniques have provoked as many a priori objections as iridencleisis. The numerous cases of raised tension and iritis, often attended by the danger of sympathetic ophthalmia, observed after accidental or post-operative iris inclusions, contraindicate any operation in which a tag of iris tissue is left under the conjunctiva in direct communication with the anterior chamber. It seems, however, not only that iridencleisis is no more dangerous than other fistulizing operations (Lagrange, 1922; Elliot, 1913), but also that this operation is suitable for many serious cases of chronic glaucoma, and in subacute glaucoma, and in glaucoma secondary to iritis, where any other fistulizing device may be dangerous.

Having analyzed for the International Congress of 1950 my personal statistics of more than 1,100 cases of fistulizing operations, I have been able to establish that in 236 cases of iridencleisis for chronic glaucoma, the percentage of successes was higher than that achieved by any other technique (Lagrange, 1922; Holth, 1930; Elliot, 1913). Moreover, a more detailed study has enabled me to confirm that the operation had usually been undertaken under the most difficult circumstances (with a restricted peripheral field or considerably reduced central vision), and also that it had been successfully used in cases of subacute glaucoma or hypertensive iritis. It seemed to me, furthermore, that my views on the indications and technique of this procedure might help to clarify the disputed question of its value.

\section{Surgical Indications}

Chronic Glaucoma.-The majority of our iridencleises were done in cases of chronic glaucoma, "wide-angle glaucoma", if we accept the classification adopted at the Chicago Symposium on primary glaucoma (1948), despite the pertinent and detailed criticism offered, particularly by Duke-Elder (1949). With variations, largely due, no doubt, to their greater or lesser natural aptitude for surgery, the oculists of different countries to-day seem to admit that in this type of glaucoma the surgical era has not come to an end, and that the

\footnotetext{
* Received for publication May 8, 1950.
} 
operation is necessary when medical treatment is non-effective or has ceased to be of value. Basing my opinion on the analysis of the 1,100 cases mentioned above, I think that "wide-angle glaucoma " should be operated upon without delay, if medical treatment fails to control the condition. In settling the right time for operation, the central visual acuity, visual fields, and ocular tension must be considered together. In the light of my own experience I hesitate to operate while the vision is above $8 / 10$, unless the peripheral field is contracting rapidly. The paracentral scotomata seem to be less significant as a pointer for operation, because they do not always yield to the normalization of pressure. The interpretation of tonometric curves also seems worthy of comment. The actual level of the pressure is not decisive. Many of our patients with relatively low pressures-from 32 to $35 \mathrm{~mm}$. $\mathrm{Hg}$ had already suffered marked shrinkage of the visual fields as well as reduced central acuity. Others, despite pressures between 40 and $45 \mathrm{~mm}$. Hg, maintained satisfactory central and peripheral acuity. In the important papers read at the Chicago Symposium I have found no mention of the relation between tonometric figures and those provided by the study of systemic and retinal arterial pressures. Bailliart's pupils, however, have all for a long time been taught the importance of that relation, and the eldest of them feels it his duty to emphasize the relatively benign effect of retinal and general arterial hypertension on ocular hypertonicity. I have seen examples of a rapid fall in central visual acuity and of a sudden contraction of the visual field after a cardiologist, with little ophthalmological training, had drastically lowered the arterial pressure. In the same way one must stress the psychological and environmental conditions in which tonometric measurements must be made. Emotion in a glaucomatous patient (vago-sympathetic imbalance) can alter the pressure. Likewise undue mobility of the globe, and lid-spasm, can influence the tonometer reading. Tonometric figures-like those of any overprecise test-must be interpreted with discrimination.

Certain associated features hasten the need for operation in glaucoma. Hereditary glaucoma is particularly serious. Psychologically, the fear of blindness in patients whose relatives have been so afflicted may be a contributory factor, although the actual state of the eye often decides the issue. One last factor-not of a scientific nature-may also necessitate early operation. A patient leading a busy life, or one who lives far out in the country, is often more difficult to keep under observation, and in such cases the insidious advance of glaucoma may render early operation imperative.

These conditions are indeed common to all operative procedures 
designed to combat chronic glaucoma. A priori fenrs of iridencleisis deterred me for a long time fron using it exrept in the most unfavourable cases, with very contracted peripheral fields and greatly reduced central acuity. Since the results have been relatively successful, as the following Table indicates, I have

TABLE

Iridencleisis in Chronic Glaucoma

\begin{tabular}{|c|c|c|c|c|c|c|c|c|}
\hline \multicolumn{5}{|c|}{ Analysis of Material } & \multirow{2}{*}{\multicolumn{2}{|c|}{$\frac{\text { Numbers }}{615}$}} & \multirow{2}{*}{\multicolumn{2}{|c|}{$\frac{\text { Percentages }}{-}$}} \\
\hline \multicolumn{5}{|c|}{ Total Casés of Chronic Glaucoma } & & & & \\
\hline \multirow{2}{*}{$\begin{array}{l}\text { Iridencleisis } \\
\text { performed }\end{array}$} & \multicolumn{2}{|c|}{ as a single operation } & $\ldots \quad$. & $\cdots \quad \cdots$ & 225 & \multirow{2}{*}{236} & \multirow{2}{*}{\multicolumn{2}{|c|}{$-\cdot$}} \\
\hline & \multicolumn{4}{|c|}{ after another fistulizing operation $\quad \ldots$} & 11 & & & \\
\hline \multirow[b]{2}{*}{$\begin{array}{c}\text { Results } \quad \ldots \\
\\
\end{array}$} & \multicolumn{4}{|c|}{ successes (ocular pressure reduced) $\quad$... } & 221 & \multirow{2}{*}{236} & $93 \cdot 6$ & \\
\hline & \multicolumn{4}{|c|}{$\begin{array}{l}\text { failures (ocular pressure remained high } \\
\text { and operations followed by ocular } \\
\text { atrophy or enucleation) } \ldots \text {... } \quad \ldots \quad \ldots\end{array}$} & 15 & & $6: 4$ & \\
\hline \multirow{8}{*}{ Visual Acuity } & \multirow{5}{*}{$\begin{array}{l}\text { before } \\
\text { operation }\end{array}$} & L.P. or H.M & I. & $\ldots$ & 55 & \multirow{5}{*}{236} & $23 \cdot 3$ & \multirow{5}{*}{100} \\
\hline & & below $3 / 10$ & $\ldots$ & $\ldots$ & 72 & & $30 \cdot 5$ & \\
\hline & & $3 / 10-5 / 10$ & $\ldots \quad$. & $\cdots$ & 44 & & $18 \cdot 6$ & \\
\hline & & $5 \cdot 5 / 10-8 / 10$ & $\ldots \quad$. & $\cdots$ & 33 & & $14: 0$ & \\
\hline & & $\begin{array}{c}\text { above } 8 / 10 \\
\text { reduced) }\end{array}$ & $\begin{array}{ll}\text { (field } & \mathbf{s} \\
\ldots & .\end{array}$ & \begin{tabular}{rr|}
\multicolumn{3}{c|}{ severely } \\
$\ldots$ & $\ldots$
\end{tabular} & 32 & & 13.6 & \\
\hline & \multirow{3}{*}{$\begin{array}{l}\text { after } \\
\text { operation }\end{array}$} & improved & $\ldots$ & $\ldots$ & 105 & \multirow{3}{*}{236} & 44.5 & \multirow{3}{*}{100} \\
\hline & & no change & $\cdots$ & ... & 94 & & 398 & \\
\hline & & lowered & $\cdots$ & $\cdots$ & 37 & & $15 \cdot 7$ & \\
\hline
\end{tabular}

increasingly used the technique in less serious cases. Even to-day, however, I use it as a last resort in the worst cases of chronic glaucoma; when both eyes must be operated on and a different technique is employed for each, iridencleisis is performed on the more seriously affected eye.

Subacute Glaucoma.-In this type (which has been termed inflammatory glaucoma, and is often classed as a " narrow angle 
glaucoma") iridencleisis seems to me again to be clearly indicated. The problem here is not merely one of opening the filtration angle, as in acute glaucoma, but also of ensuring permanent fistulization. It is known that simple iridectomy, which is usually sufficient to deal with acute exacerbations of hypertension, is inadequate in combating the residue of chronic hypertension which distinguishes this type of glaucoma from the true acute variety. It is well-known, moreover, that sclerectoiridectomy performed in an acute phase usually ends in obstruction. For a long time it has been my practice to perform a preliminary iridectomy in an oblique meridian (at 2 or 10 o'clock) and then, when the eye is quiet again, to carry out a fistulizing operation on the other side of the vertical meridian. It seems to me that iridencleisis, even when performed in an acute phase, is usually adequate to overcome simultaneously the phenomena of chronic hypertension, and I now use it regularly in treating such cases.

Hypertensive Uveitis.-Marcel Kalt, in his excellent report presented in 1949 to the Société française d'Ophtalmologie, follows Weekers (1947) in advising the use of iridencleisis in hypertensive uveitis, and I support him in this opinion. One reservation must, however, be made. Uveitis with hypertension occurs in two essentially different types of case. In some cases, the hypertension is an integral element of the syndrome and is present from the onset, as if vago-sympathetic imbalance and oedema of the vitreous were essential characteristics of the uveal disturbance. In other cases, the hypertensive phenomena, developing later, are secondary to pupillary occlusion. This is the situation in certain cases of syphilitic and of fibrinous iritis. In this second type of case, iridectomy, less traumatizing even.than iridencleisis, is sufficient, provided that it be performed in time, since there comes a time when it can no longer be risked. It would be correct to say that iridectomy must prevent rather than treat seclusion or occlusion of the pupil.

Chronic glaucoma, subacute glaucoma, hypertensive iritisthese are the major indications for iridencleisis. The severity of these conditions, however, necessitates a rigorous surgical technique upon which I feel bound to insist.

\section{Technique}

In my belief, iridencleisis, the value of which is great but more or less comparable with that of other fistulizing operations in the early stages of chronic simple glaucoma, is the best operation for chronic glaucoma of long standing, in which there is a marked 
reduction of central vision and a large degree of contraction of the visual field. It has been shown that it should also be used in cases of subacute glaucoma and of hypertensive iritis. For this reason it must be performed with great care, operative trauma being reduced to a minimum and haemorrhage avoided at all costs ; the latter may arise from dilatation of blood vessels or from rapid decompression.

Induction of anaesthesia may be difficult with red eyes, which often-require operation. Adrenalin, ephedrine, and privine should be instilled for a prolonged period. The retrobulbar injection should consist of equal parts of 4 per cent. procaine and of ephedrine, with a few drops of adrenaline.

I usually increase the coagulability of the blood by giving two injections of " coagulène" (platelets and thrombin) and three injections of " adrénoxyl" (monosemicarbazone of adrenochrome, 0.05 ; sodium chloride, 0:010 ; acid sodium and potassium phosphate, 0.058; potassium dihydrogen phosphate, 0.035; distilled sterile water, to $100 \mathrm{ml}$.).

The eyeball is firmly fixed by a stitch placed in the superior rectus, and the bulbar conjunctiva is dissected with scissors and then with a Desmarre scarifier, dissection being carried to the limbus as in any other fistulizing operation. Haemorrhage from the scleral vessels is controlled by application of the point of a strabismus hook at dull red heat. I almost always use the incisio $a b$ externo of Gayet, with a thin-bladed knife (razor blade). The linear incision, $4 \mathrm{~mm}$. long, is made tangentially to the limbus and $1.5 \mathrm{~mm}$. above it, at the level of the root of the iris. It is performed very carefully like a cyclodialysis incision, but here bulging of the root of the iris serves as a warning that the sclera has been pierced. When the prolapsed iris root is the size of a pin-head, the operation is stopped for 30 or 40 seconds to allow the gradual escape of aqueous; this procedure appears to be extremely important.

If the atrophy of the iris is too great or there are dense adhesions to the lens capsule, spontaneous prolapse of the iris may not occur. When the aqueous has been slowly evacuated, slight pressure on the cornea often causes prolapse of the iris root into the wound, with negligible trauma. I should add that advanced iris atrophy is of bad prognostic significance, and in these cases the technique of operation should be modified. I shall refer to this again later in the paper.

When the scleral incision has been completed, the iris usually protrudes in spite of the loss of aqueous. It is then retained by a rather special method, similar to that described by Pillat (Meller and Böck, 1946). The aim is to avoid return of 
the iris into the anterior chamber. This is easily achieved by dividing the sphincter, without touching the base of the iris, which should be allowed to form a lip over the scleral wound, thus preventing its closure. I prefer this technique to the dilaceration recommended by Weekers-a dilaceration which, in my view, is more likely to lead to haemorrhage than the clean section used by Pillat and myself. The difference between Pillat's technique and mine is slight-I section the iris from bottom to top, from the pupillary margin towards the lesser circle. The conjunctival flap is replaced with a continuous silk suture without knots at the ends. Except in cases of subacute glaucoma, I usually instil a drop of atropine at the end of the operation.

Haemorrhage is usually slight if the precautions described above are observed: increase of coagulability of the blood by drugs, careful haemostasis of scleral vessels, slow release of the aqueous, and clean sectioning of the iris sphincter. I have sometimes used diathermy for the last step when, under the slit-lamp microscope, the vessels of the iris appeared excessively dilated.

Advanced iris atrophy seems to me to endanger filtration. In these cases I modify my technique. After turning back the conjunctival flap, I make a second incision parallel with and $1.5 \mathrm{~mm}$. below the first incision, and dissect up a thin band of sclera. I then cut the iris right to its base, and wedge the free margins into the angles of the resected zone. This relatively simple modification has often permitted good results to be obtained in cases in which iridencleisis performed by my usual technique would have seemed doomed to failure.

I do not wish to refer again to the detailed statistical analysis of my cases of iridencleisis. For the statistics to be of value, the conditions in which the method was practised must be studied. In brief, it can be said that, out of 236 cases of iridencleisis for chronic glaucoma in which the results could be checked, there were fifteen failures ( 6.4 per cent.). In 85.3 per cent. of cases we were able to maintain or improve visual acuity, visual field, and ocular pressure. In almost all of these cases, there was permanent filtration, so closely comparable with the filtration obtained by Lagrange's operation that we could not always tell which technique had been used without consulting the case history. In eight cases I had to perform an enucleation in order to prevent the development of sympathetic ophthalmia, a complication which I have never encountered.

The results of the use of iridencleisis in hypertensive iritis are certainly less favourable. In subacute glaucoma, on the other hand, they are at least not inferior to those obtained in the treatment of chronic glaucoma. 
Until fuller knowledge of the causes and mechanisms of the different types of ocular hypertension allows us to obtain equally good results with medical treatment alone, I am convinced of the injustice of many of the criticisms raised against the surgical treatment of the disease. Techniques improve, and must continue to do so, but the idea, which Lagrange had the good fortune to put into practice first, of permanent drainage of the aqueous into the sub-conjunctival space has already enabled a large number of patients to conserve their vision. Iridencleisis seems to me to permit the extension of these results to cases in which other techniques of fistulization would be ineffective.

\section{REFERENCES}

Duke-Elder, S. (1949). Arch. Ophthal., Chicago, 42, 538.

Elliot, R. H. (1913). "Sclero-Corneal Trephining in the Operative Treatment of Glaucoma". London.

Friedenwald, J. S., Kronfeld, P. C., Sheie, H. G., Dunnington, J. H., Chandler, P. A., and Vail, D. (1949). Trans. Amer. Acad. Ophthal. Otolaryng., 53, 169.

Holth, S. (1930). Arch. Ophthal., Chicago, 4, 803.

Kalt, M. (1949). "Les Uvéites Hypertensives". Masson, Paris.

LAgrange, F. (1922). "Du Glaucome et l'Hypotonie: Leur Traitement Chirugical". Paris.

Meller, J. and Böck. J. (1946). "Augenärtzliche Eingriffe”. 5th ed., Springer, Vienna.

Pillat, A. In Meller and Böck, p. 315.

WeEkers, L,, and WeEkers, R. (1947). Ann. Oculist., Paris, 180, 76.

, (1948). British Journal of Ophthalmology, 32, 904. 